\title{
The Seasonal Variations of Surface Currents in the Tropical Atlantic Ocean: A Comparison of Ship Drift Data With Results From a General Circulation Model
}

\author{
P. L. RichaRDSON \\ Woods Hole Oceanographic Institution, Woods Hole, Massachusetts
}

\author{
S. G. H. Philander
}

Geophysical Fluid Dynamics Laboratory, NOAA, Princeton University, Princeton, New Jersey

\begin{abstract}
Historical ship drifts from the tropical Atlantic Ocean are compared with surface currents from a general circulation model forced with monthly mean climatological winds. The model accurately reproduces the spatial structure of the currents and its time dependence, which varies considerably from the eastern side of the basin, where a semiannual harmonic is prominent, to the western side, where an annual harmonic is dominant. However, the amplitude of the simulated surface currents in the western side of the basin is too large. Mixing processes in the model appear to be too weak, especially when the winds are weak in regions where the thermocline is deep. High-frequency fluctuations of the winds need to be taken into account, and parameterization of the mixing needs to be improved, especially when the Richardson number is small.
\end{abstract}

\section{INTRODUCTION}

A general circulation model of the tropical oceans appears to be realistic because it reproduces the principal features of El Niño of 1982-1983 [Philander and Seigel, 1985] and of the seasonal cycle in the tropical Atlantic Ocean [Philander and Pacanowski, 1984, 1986]. Quantitative comparison between measurements and results from the model have been limited. Garzoli and Philander [1985] compare vertically integrated temperature variations from the model with inverted echo sounder measurements of seasonal changes in the thermal structure of the tropical Atlantic. Philander and Seigel [1985] note that the model realistically simulates the phase and amplitude of the current fluctuations observed on the equator at $160^{\circ} \mathrm{W}$ [Firing et al., 1983] and at $95^{\circ} \mathrm{W}$ [Halpern, 1986] during El Niño of 1982-1983. In this paper we describe a more extensive comparison between simulated and observed currents. The observations describe seasonal changes of the surface currents in the tropical Atlantic Ocean on the basis of historical ship drifts [Richardson and McKee, 1984]. The simulated currents are from a calculation in which a model of the tropical Atlantic is forced with climatological winds [Philander and Pacanowski, 1986].

Sections 2 and 3 of this paper describe the ship drift data and the model, respectively. Section 4 is a presentation of the results, and section 5 discusses the implications of the results.

\section{ShIP Drift Data}

The ship drift velocity data were obtained from the U.S. Naval Oceanographic Office. They consist of approximately 438,000 individual observations within the region bounded by $20^{\circ} \mathrm{S}$ to $20^{\circ} \mathrm{N}, 10^{\circ} \mathrm{E}$ to $70^{\circ} \mathrm{W}$, and the coasts of Africa and South America. Each ship drift measurement of surface current velocity consists of the vector difference between

Copyright 1987 by the American Geophysical Union.

Paper number 6C0591.

0148-0227/87/006C-0591\$05.00 the velocity of a ship determined from two position fixes and the average estimated velocity of the ship through the water during the same time interval, usually 12-24 hours. The vector difference is considered to be due to a surface current. Each measurement is an average (1) over the depth of the ship's hull and (2) along the ship's path between fixes, usually a few hundred kilometers. Thus only large-scale features, greater than a few hundred kilometers, can be resolved using this technique.

A single velocity measurement is estimated to have a random error of $\sim 20 \mathrm{~cm} \mathrm{~s}^{-1}$, attributable to incorrect position fixes and dead reckoning, for example [Richardson and McKee, 1984]. A comparison of the ship drift data with data from drogued drifting buoys in the North Equatorial Countercurrent shows that the amplitude and phase of the seasonal variations agree well (P. L. Richardson and G. Reverdin, Seasonal cycle of velocity in the Atlantic North Equatorial Countercurrent as measured by surface drifters, current meters, and ship drifts, submitted to Journal of Geophysical Research, 1986). This suggests that ship drifts are not excessively affected by windage.

Most ships followed standard sailing routes along which the data density is as high as $100-500$ observations per $1^{\circ}$ square (Figure 1). Fortunately, many routes follow coasts, and many others cut across the central equatorial region, covering both the boundaries and the internal regions. The data were obtained over a period of 100 years from 1875 until 1976. The number of measurements peaked between 1920 and 1940 so that the results strongly reflect conditions during these years. The data are nearly evenly distributed seasonally. The average number of observations each month is $\sim 35,000$. December has the fewest with 27,000, and August has the most with 41,000 .

In order to calculate and map mean velocity values, individual velocity values were grouped into space-time boxes of various sizes. First, 12 monthly maps were made from $2^{\circ}$ latitude $\times 5^{\circ}$ longitude boxes. Some of the monthly maps were similar. These were grouped together to produce 


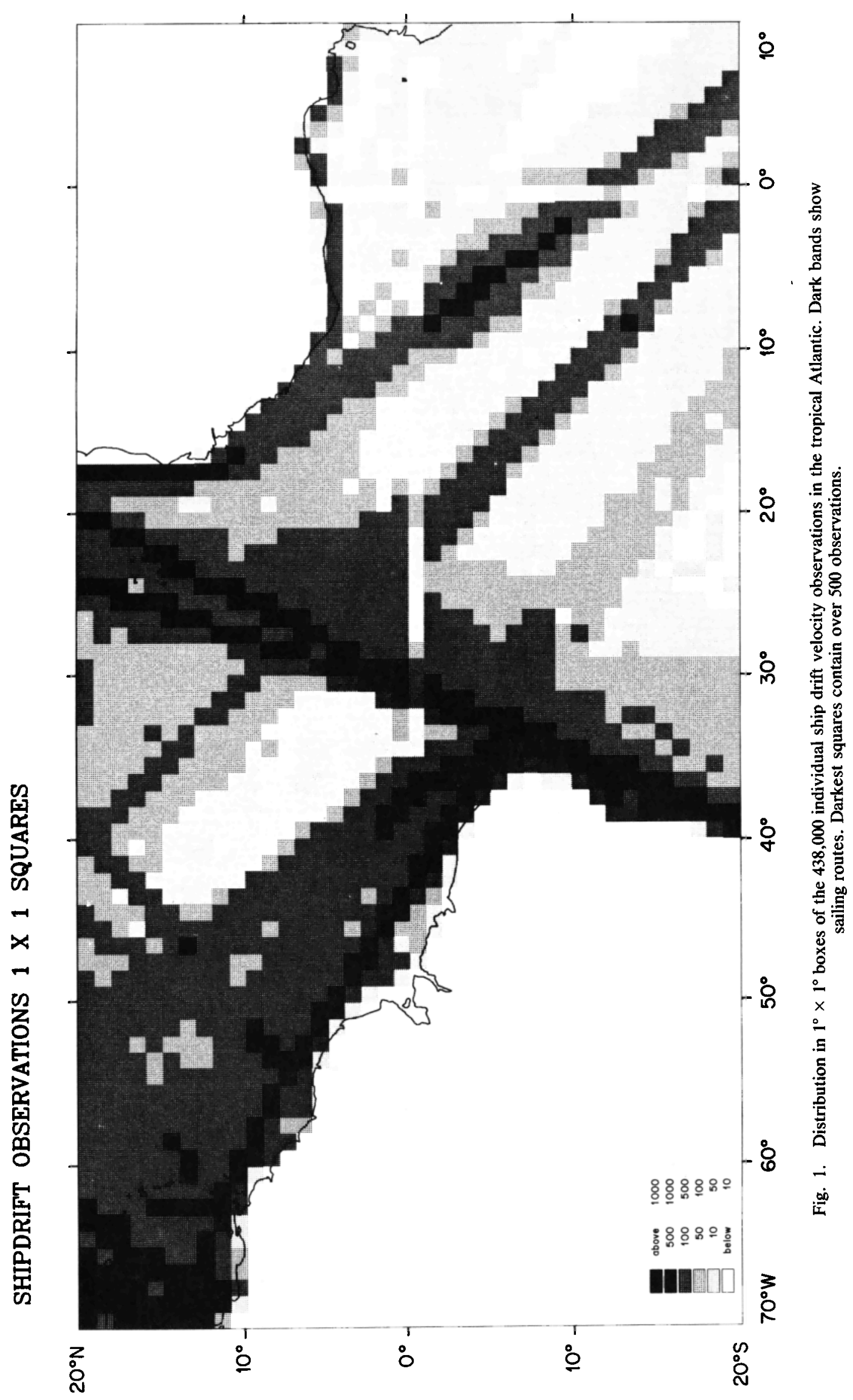



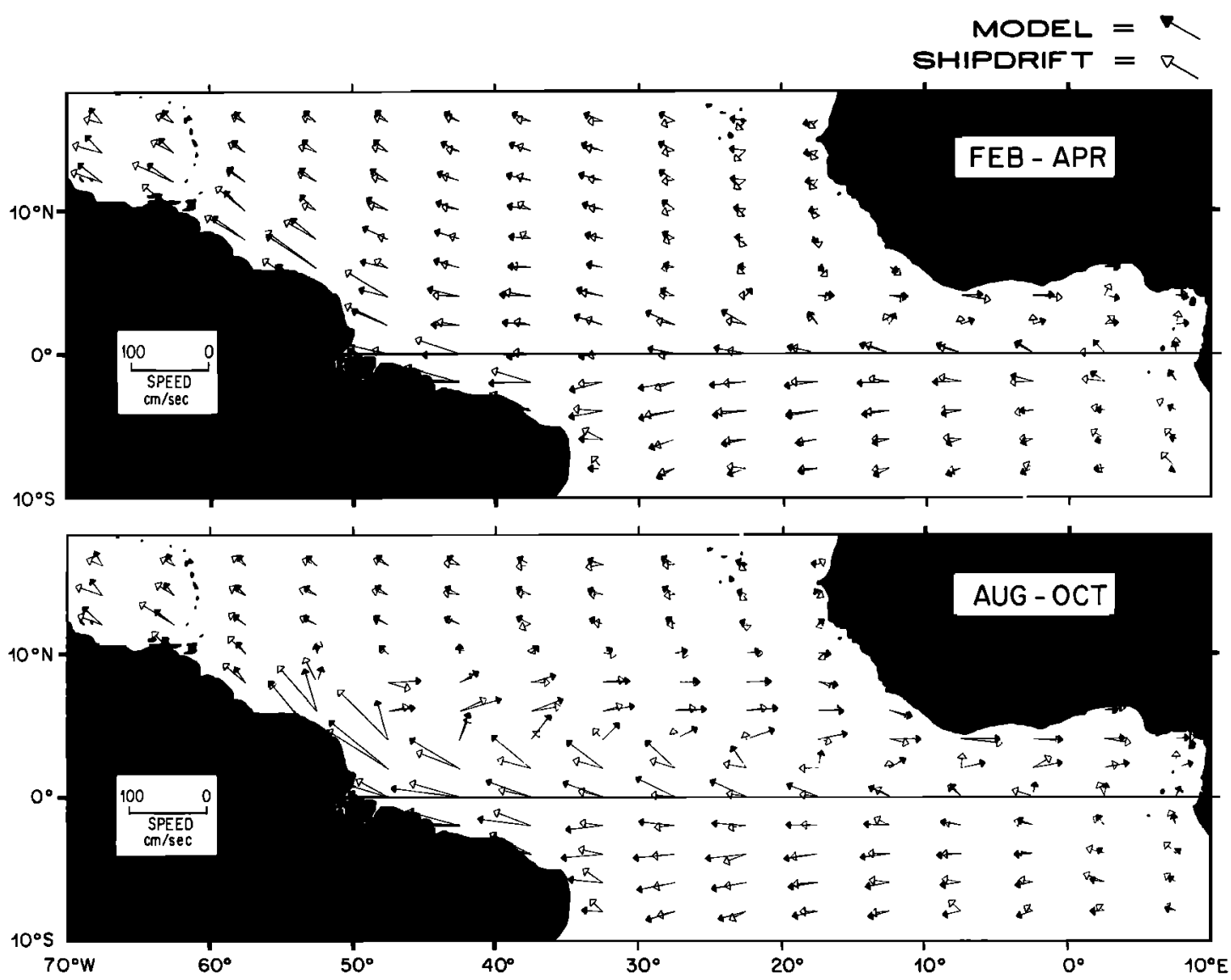

Fig. 2. Velocity vectors for February through April and August through October, calculated by grouping ship drift and model (upper layer) velocities into $2^{\circ} \times 5^{\circ}$ boxes. Speed is given by the length of each vector.

characteristic velocity fields showing the maximum and minimum velocity in the North Equatorial Countercurrent (NECC) in August-October and February-April. Monthly average values were used to calculate seasonal variations and annual means. A more complete discussion of the data, calculations, and errors is given by Richardson and McKee [1984] and Richardson and Walsh [1986].

\section{THE MODEL}

The model extends from $28^{\circ} \mathrm{S}$ to $50^{\circ} \mathrm{N}$, but the region of principal interest, with high spatial resolution, is the tropics. In the east-west direction the resolution is $1^{\circ}$ longitude; in the north-south direction it is $37 \mathrm{~km}$ between $10^{\circ} \mathrm{N}$ and $10^{\circ} \mathrm{S}$ and then increases gradually. In the vertical there are 27 layers; the upper $100 \mathrm{~m}$ have a resolution of $10 \mathrm{~m}$. The main comparison is between ship drifts and the upper $10 \mathrm{~m}$ in the model.

The primitive equations are solved numerically by means of finite differencing methods discussed by Bryan [1969]. The use of Richardson number dependent vertical mixing coefficients is explained in detail by Pacanowski and Philander [1981]. In the upper $10 \mathrm{~m}$ of the model the coefficient of vertical eddy viscosity has a minimum value of $10 \mathrm{~cm}^{2} \mathrm{~s}^{-1}$ to compensate for mixing by the high-frequency wind fluctuations which are absent from the monthly mean winds. In the deep ocean where vertical mixing is negligible, vertical viscosity has the value of molecular viscosity. The coeffi- cients of horizontal eddy viscosity and diffusivity are $2 \times 10^{7}$ $\mathrm{cm}^{2} \mathrm{~s}^{-1}$ equatorward of $10^{\circ}$ latitude; poleward of this they increase gradually to a value of $7 \times 10^{7} \mathrm{~cm}^{2} \mathrm{~s}^{-1}$ at $50^{\circ} \mathrm{N}$. Unstable temperature gradients are eliminated instantaneously by mixing heat vertically to a depth that ensures a stable density gradient.

The imposed surface wind stress is the monthly mean climatological winds described by Hellerman and Rosenstein [1983]. The heat flux across the surface is parameterized as was described by Philander and Pacanowski [1986]. The initial conditions in the model correspond to the observed (climatological) thermal conditions for January [Levitus, 1982]. The model velocity field reaches equilibrium approximately 1 year after the calculations are started. The time step for the numerical integrations is $40 \mathrm{~min}$. Data averaged over 3-day periods during the third year of integrations were saved for use in the calculations to be described next.

\section{Results}

Seasonal changes in the surface winds, which drive the oceanic circulation in the tropical Atlantic Ocean, are associated primarily with the meridional migrations of the Intertropical Convergence Zone (ITCZ), onto which the southeast and northeast trades converge. When the ITCZ is close to the equator, in March and April, the winds there are relaxed and the surface currents are relatively weak and westward everywhere except to the north of the equator in 


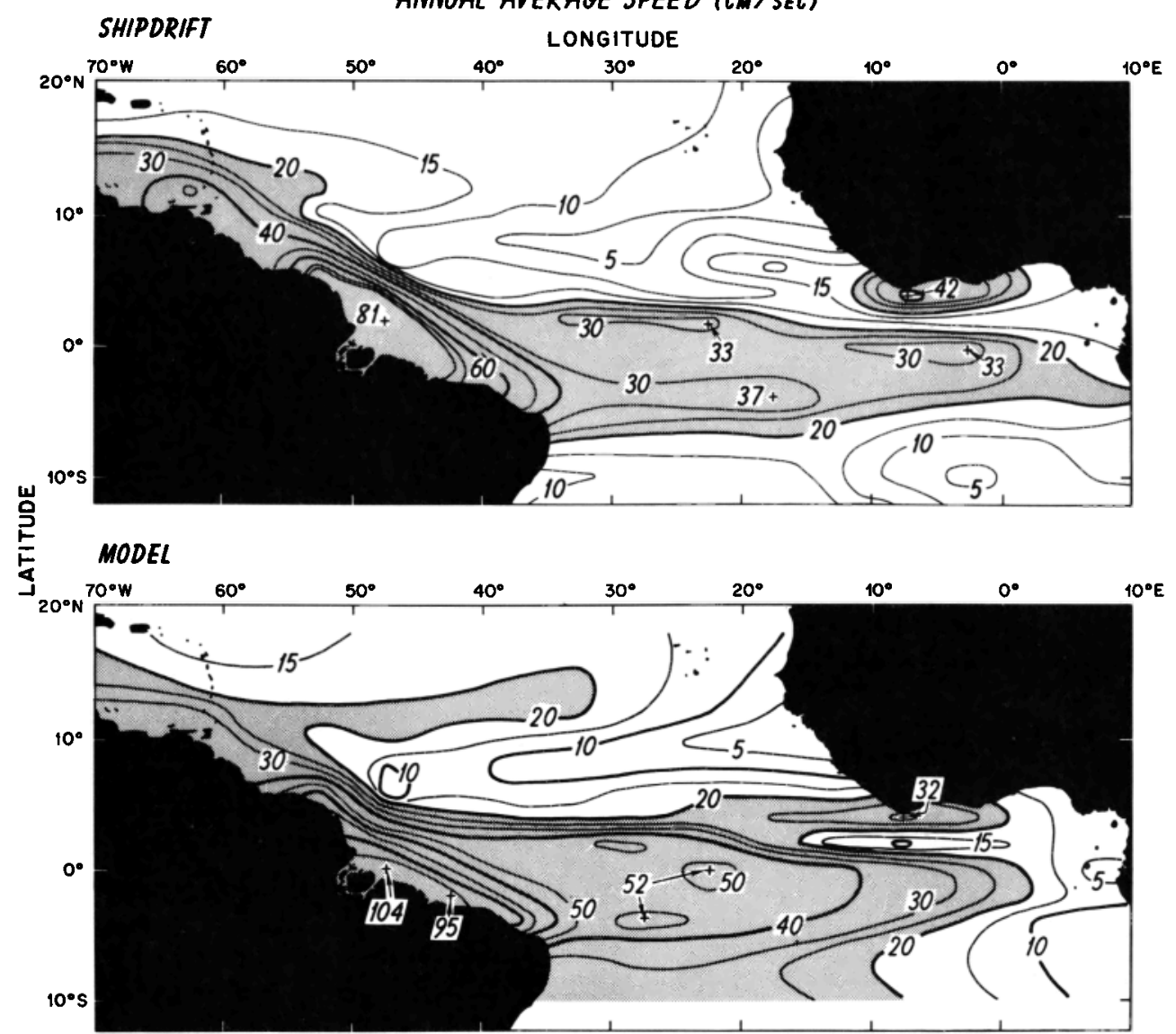

Fig. 3. Magnitude of the annual average velocity in $2^{\circ} \times 5^{\circ}$ boxes. Speeds greater than $20 \mathrm{~cm} \mathrm{~s}^{-1}$ are shaded to emphasize the swiftest currents.

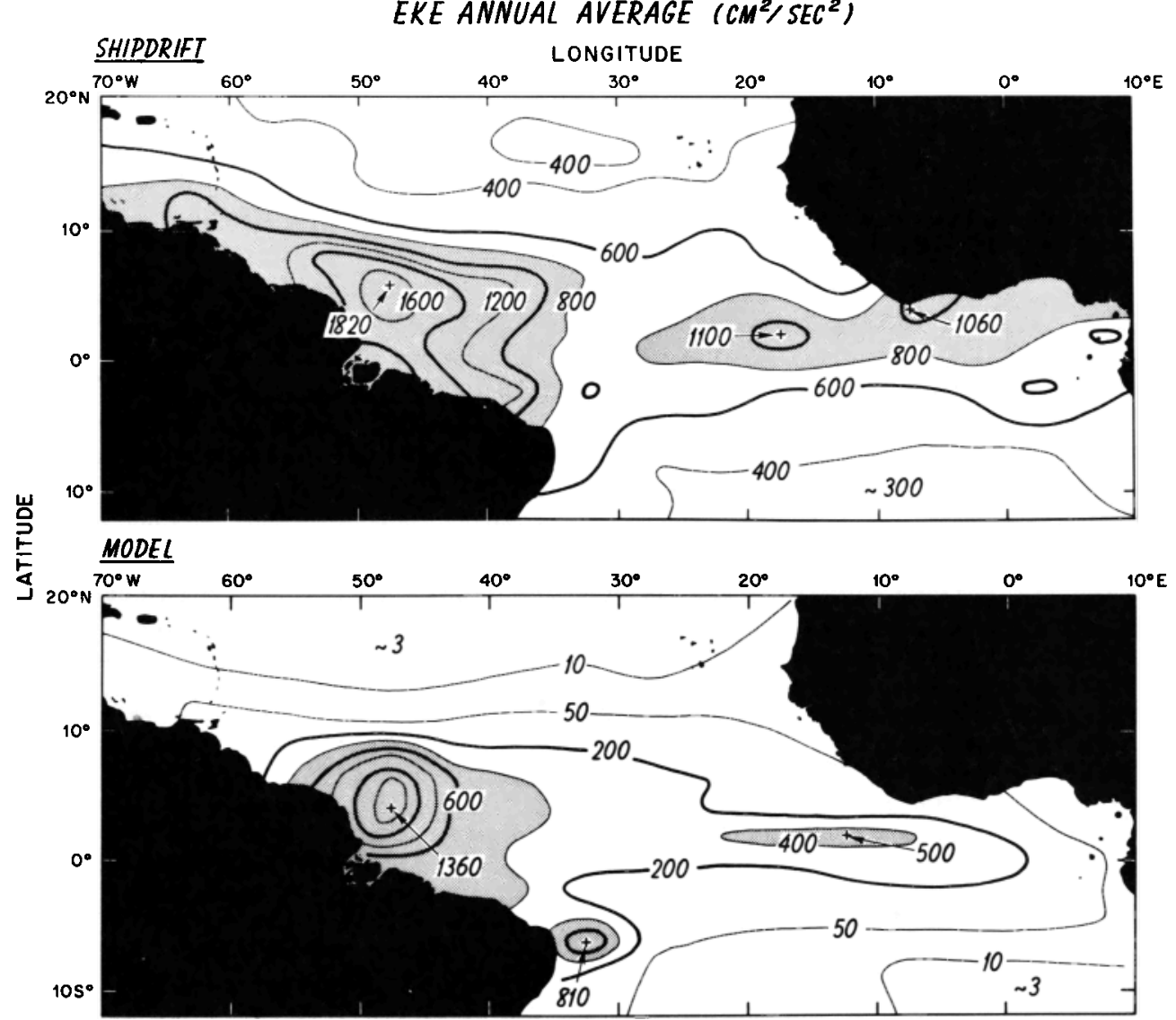

Fig. 4. Distribution of eddy kinetic energy based on all observations in each $2^{\circ} \times 5^{\circ}$ box. Eddy kinetic energy equals one half of the sum of the average $u$ and $v$ variances. 


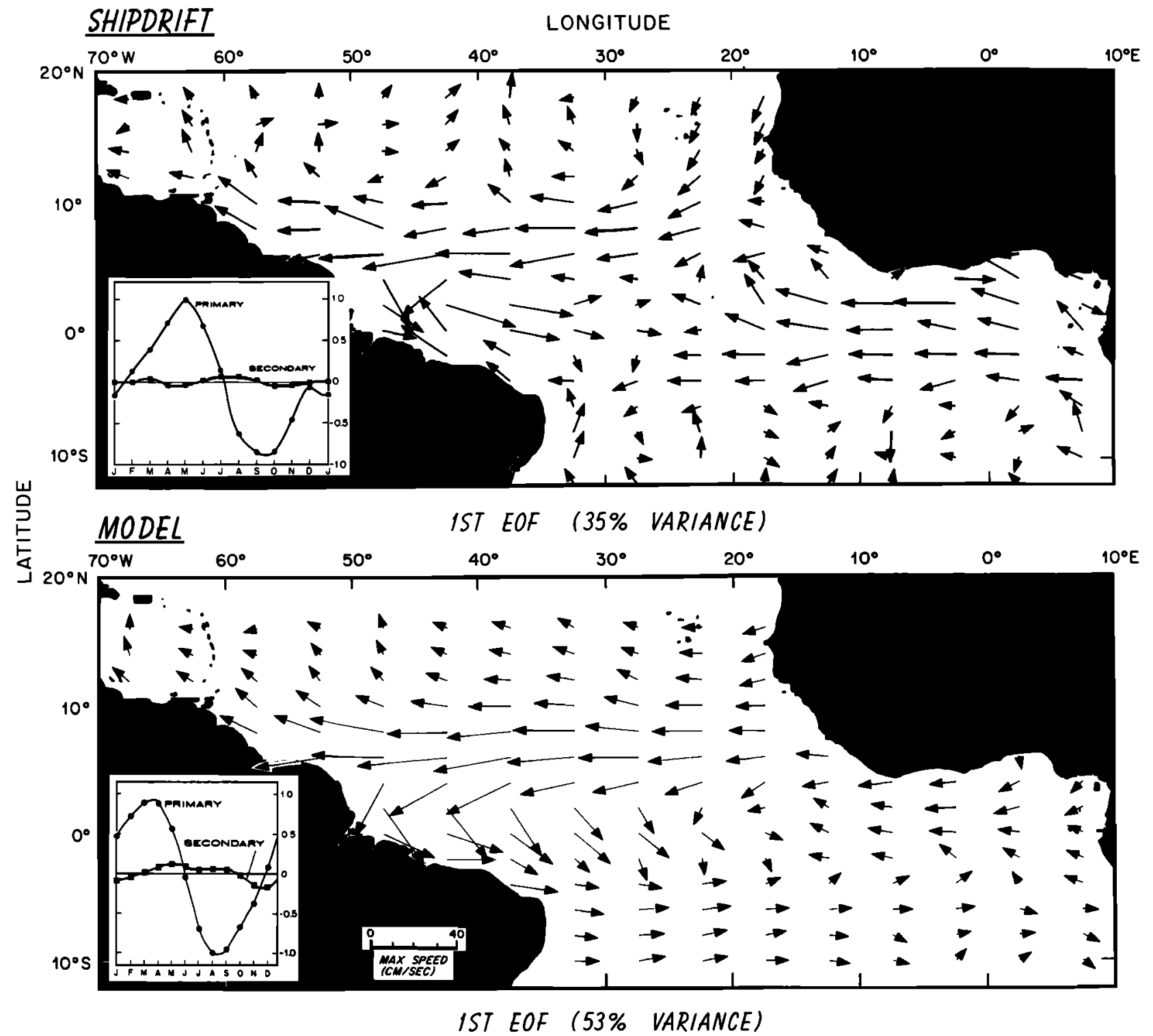

Fig. 5. Velocity vectors and times series of the first empirical orthogonal function, which accounts for $53 \%$ of the variance in the seasonal variation in model simulations and $35 \%$ in ship drifts. The vectors are multiplied by the time series given in the inset in the lower left corners. The primary series correspond to the component parallel to the vectors; the secondary is normal to the vectors and causes them to rotate [see Richardson and Walsh, 1986]. Since the magnitudes of the primary series are much larger than those of the secondary series, the variation is principally along the vectors.

the Gulf of Guinea. The northward movement of the ITCZ in May and the associated intensification of the southeast trades result in a dramatic change in the surface currents. To the south of $3^{\circ} \mathrm{N}$, approximately, the westward South Equatorial Current intensifies considerably, but between $3^{\circ} \mathrm{N}$ and $10^{\circ} \mathrm{N}$ the westward surface flow becomes the strong eastward North Equatorial Countercurrent. Figure 2 shows that the model simulates these seasonal changes realistically. Discrepancies between the ship drift data and the model are most serious during the boreal summer in the region just north of the equator near the coast of Brazil. This, however, is a region with a complex flow pattern which has large spatial gradients because the Brazilian Coastal Current veers offshore between $5^{\circ} \mathrm{N}$ and $10^{\circ} \mathrm{N}$ from June until January, when an eddy forms near the coast of Brazil [Bruce and Kerling, 1984].

The mean current speeds and their standard deviations for the model and ship drift data are shown in Figures 3 and 4. The model is seen to simulate the spatial distribution of the mean speed accurately, but in the western side of the basin the speeds of the model are too high. This feature will shortly be explored in more detail. The variability in the ship drift data has a far greater amplitude than the variability in the model, but the spatial patterns of the variability are similar. This suggests that the discrepancy in the amplitudes may be caused by noise in the ship drift data (errors plus interannual variations and high-frequency oscillations not in the model). If the random errors of $20 \mathrm{~cm} \mathrm{~s}^{-1}$ are taken into account, 


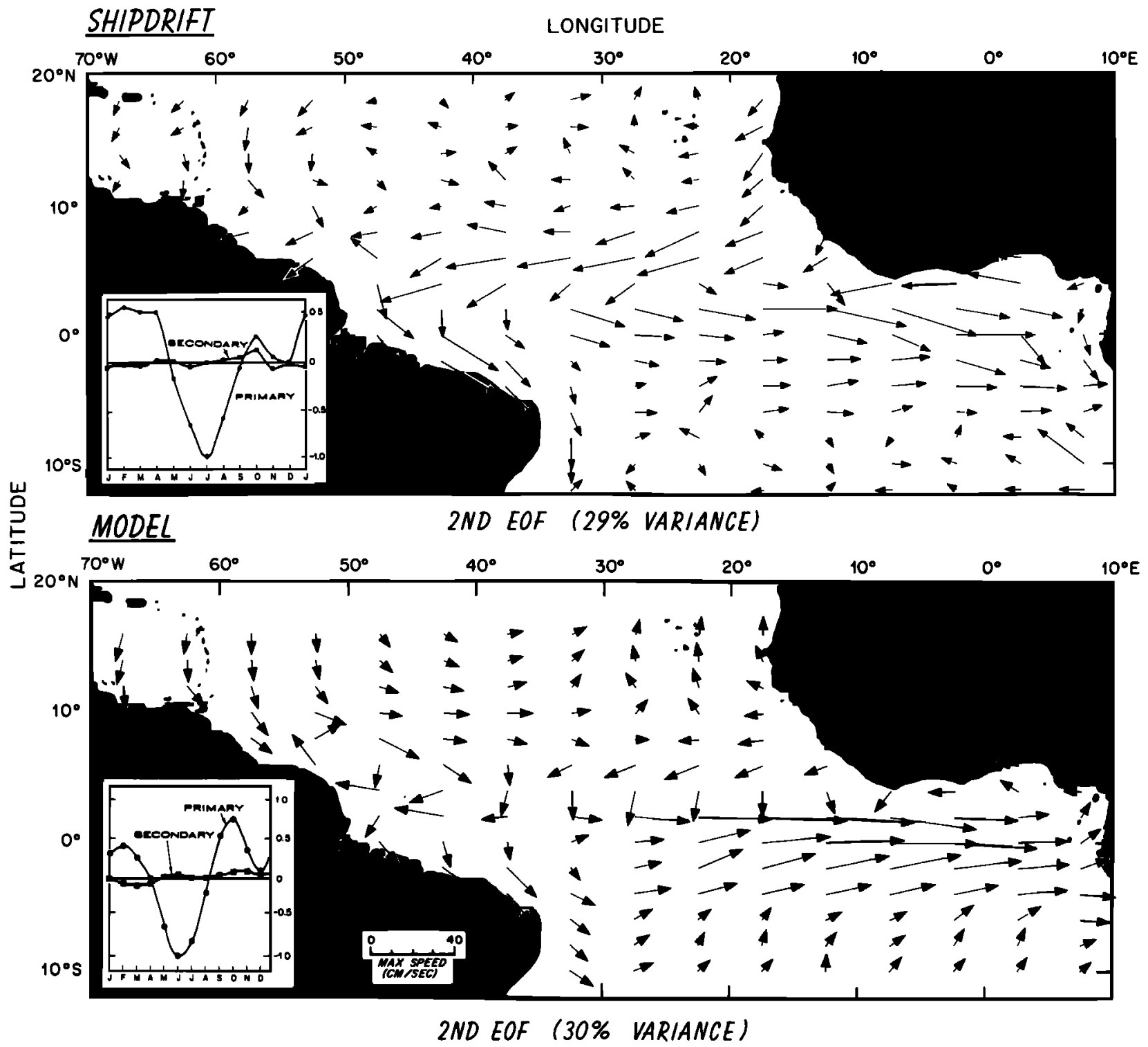

Fig. 6. Velocity vectors of the second empirical orthogonal function, which accounts for $30 \%$ of the model and $29 \%$ of the ship drift seasonal variation.

then the model simulates the spatial distribution and amplitude of the variability quite well. (Keep in mind that the model is forced with climatological monthly mean winds which have no high-frequency components.)

Empirical orthogonal functions proved an efficient representation of the variability of the surface currents in the model. The first two functions account for $83 \%$ of the variance of the model but for only $64 \%$ of the variance of the ship drift data (Figures 5 and 6). The spatial structures of the ship drift and model functions are very similar. The time dependence of the functions for the ship drift data is almost identical to the time dependence of the functions for the model. In other words, the model is remarkably good at reproducing both the spatial and temporal structure of the surface currents, but as was mentioned before, it overestimates the amplitude, especially in the western side of the basin.
The agreement between the simulated and observed phase and amplitude of the semiannual cycle in the Gulf of Guinea is remarkable (Figure 7). In the western side of the basin, on the other hand, the eastward North Equatorial Countercurrent and the South Equatorial Current are too intense in the model although the simulation of the phase of the seasonal variations is excellent (Figure 8). Although the latitudinal variations of the average surface currents in the west are reproduced extremely well in Figure 9, the discrepancies between the amplitudes in this figure amount to a factor of 2 approximately.

The dominant mode of variability in the tropical Atlantic Ocean, other than the seasonal cycle, is an instability associated with the latitudinal shear of the near equatorial currents [Weisberg, 1984; Philander et al., 1986]. These waves have a period of the order of a month, have a wavelength of $1000 \mathrm{~km}$ approximately, and have westward 
phase propagation. The variance in Figure 10 is a measure of the amplitude of these waves near $28^{\circ} \mathrm{W}$. If allowance is made for the higher noise level in the ship drift data (we commented earlier that errors, interannual variations and high frequency fluctuations contribute approximately 400 $\mathrm{cm}^{2} \mathrm{~s}^{-2}$ ), then the model results agree reasonably well with the ship drift data. In the model the peak amplitude is attained a month later (August) than in the ship drift data. The use of climatological winds to force the model may be a factor in this discrepancy. More puzzling is the equatorward shift of the maximum amplitude in the model. The waves depend primarily on the latitudinal shear of the currents, but the shear, though too large, is simulated well (Figure 9). We have no explanation for this difference between the model and ship drift data.

The longitude and timing of the instability waves is further investigated in Figure 11. In the model the simulated waves occur west of $20^{\circ} \mathrm{W}$ and their amplitude peaks near $32^{\circ} \mathrm{W}$ in August. In ship drifts the (inferred) waves occur all along the equatorial band from the Gulf of Guinea $\left(10^{\circ} \mathrm{W}\right)$ to the western boundary with peaks near $18^{\circ} \mathrm{W}$ in July and $42^{\circ} \mathrm{W}$ in June. The western peak is not solely due to instability waves, since the startup of the NECC occurs near $42^{\circ} \mathrm{W}, 1^{\circ} \mathrm{N}$ to $3^{\circ} \mathrm{N}$ in May and June [see Richardson and McKee, 1984, Figure 7]. Spatial averaging of ship drifts and interannual variations could also contribute to the variance in this complicated western region. The peak in the east (near $18^{\circ} \mathrm{W}$ ) has been confirmed by Seasonal Response of the Equatorial Atlantic (SEQUAL) and Programme Francais Océan-Climat en Atlantique Equatorial (FOCAL) measurements; instability waves were observed in June, July, and August 1983 extending from at least $0^{\circ} \mathrm{W}$ to $30^{\circ} \mathrm{W}$ [Weisberg, 1984; McPhaden et al., 1984; Legeckis and Reverdin, 1987]. The main deficiency in the simulated waves in the model is their absence in the east $\left(10^{\circ}-20^{\circ} \mathrm{W}\right)$ where they have been documented. This deficiency may be linked to the overestimate of simulated currents in the west as was noted above.

To summarize, the model accurately reproduces the spatial structure of the surface currents and their time dependence, even though this time dependence varies enormously from the western side of the basin, where an annual harmonic is dominant, to the eastern side, where a semiannual harmonic is prominent. However, the amplitude of the simulated currents in the western side of the basin is too large by a factor of 2 approximately.

\section{Discussion}

There are a number of factors that cause errors in the simulation. The climatological winds, for example, have inaccuracies. D E. Harrison (private communication, 1986) estimates that the value for the drag coefficient in Hellerman and Rosenstein's [1983] climatological winds, which drive the model, may be $20 \%$ too high. Another factor, probably the most important one, is the parameterization of mixing processes. If the currents are too intense in the model then the mixing processes are presumably too weak. This problem is likely to be severe when the winds are weak because the model is forced with climatological monthly mean winds. The winds in reality have considerable high-frequency fluctuations which do not drive large-scale currents but which stir the upper ocean. An attempt was made to compensate for the deficiency in the winds that drive the model by

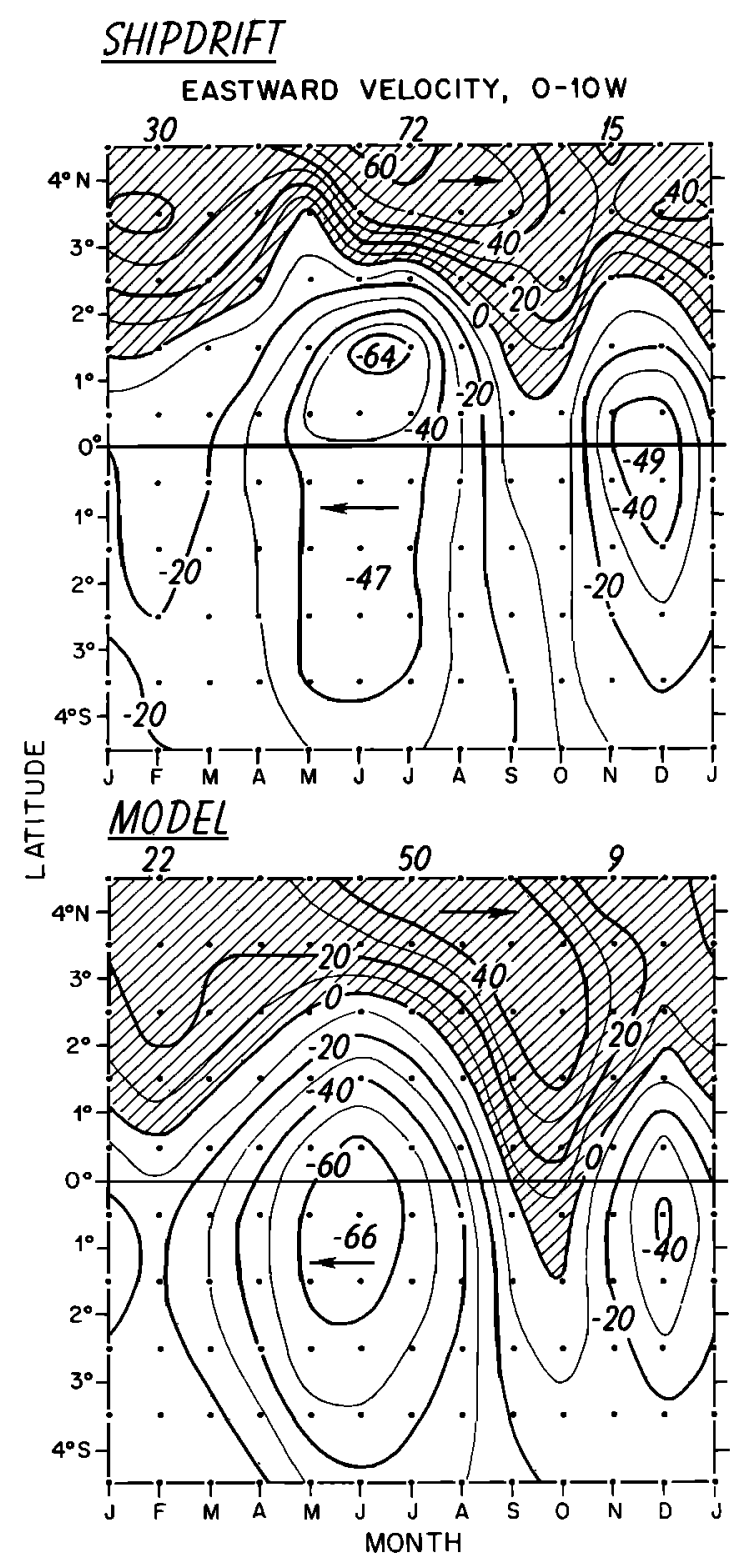

Fig. 7. Time-latitude plot of eastward velocity (in centimeters per second) in the Gulf of Guinea. Individual velocity values were grouped into $1^{\circ}$ latitude by $10^{\circ}$ longitude boxes, and monthly averages were calculated.

assigning the coefficient of vertical eddy viscosity a minimum value of $10 \mathrm{~cm}^{2} \mathrm{~s}^{-1}$ in the upper $15 \mathrm{~m}$ of the model. Apparently this value should have been higher and should have extended over a greater depth. The depth to which this stirring penetrates should depend on the vertical stratification of the ocean. It will therefore remain shallow in the Gulf of Guinea, where the thermocline is shallow, but will increase in a westward direction because the thermocline deepens in that direction. Difficulties associated with the absence of wind noise are most acute where the thermocline is deep, at times when the winds are weak, because such weak winds will unrealistically persist for a month in the model. Consider as an example the neighborhood of $6^{\circ} \mathrm{N}$, $38^{\circ} \mathrm{W}$, where the thermocline is deep. Figure 12 shows the hodographs of the currents for that region of the model and also shows the ship drift current vectors. When the local 


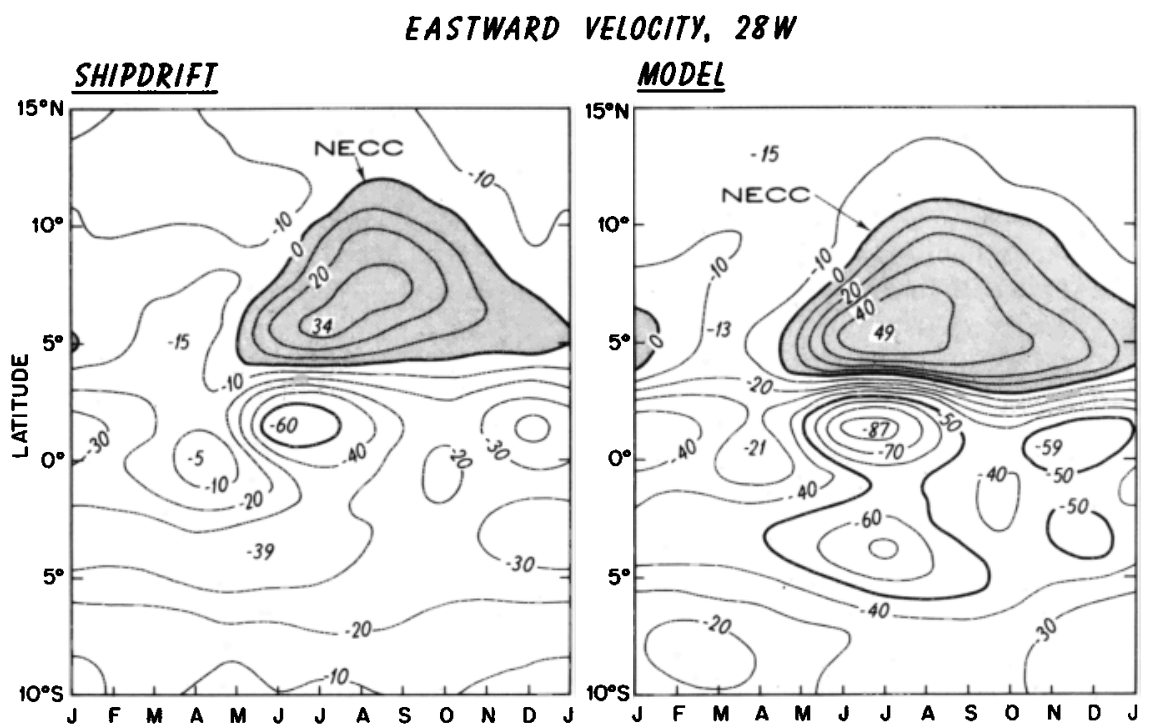

Fig. 8. Time-latitude plot of eastward velocity (in centimeters per second) in the band $23^{\circ}-33^{\circ} \mathrm{W}$. Individual velocity values were grouped into $1^{\circ}$ latitude by $10^{\circ}$ longitude boxes, and monthly averages were calculated.

wind is intense, in April, the surface current in the model is realistic, but when the wind is weak, in July, the surface current in the model is too intense and will become more realistic if there is mixing to depth greater than $35 \mathrm{~m}$. A

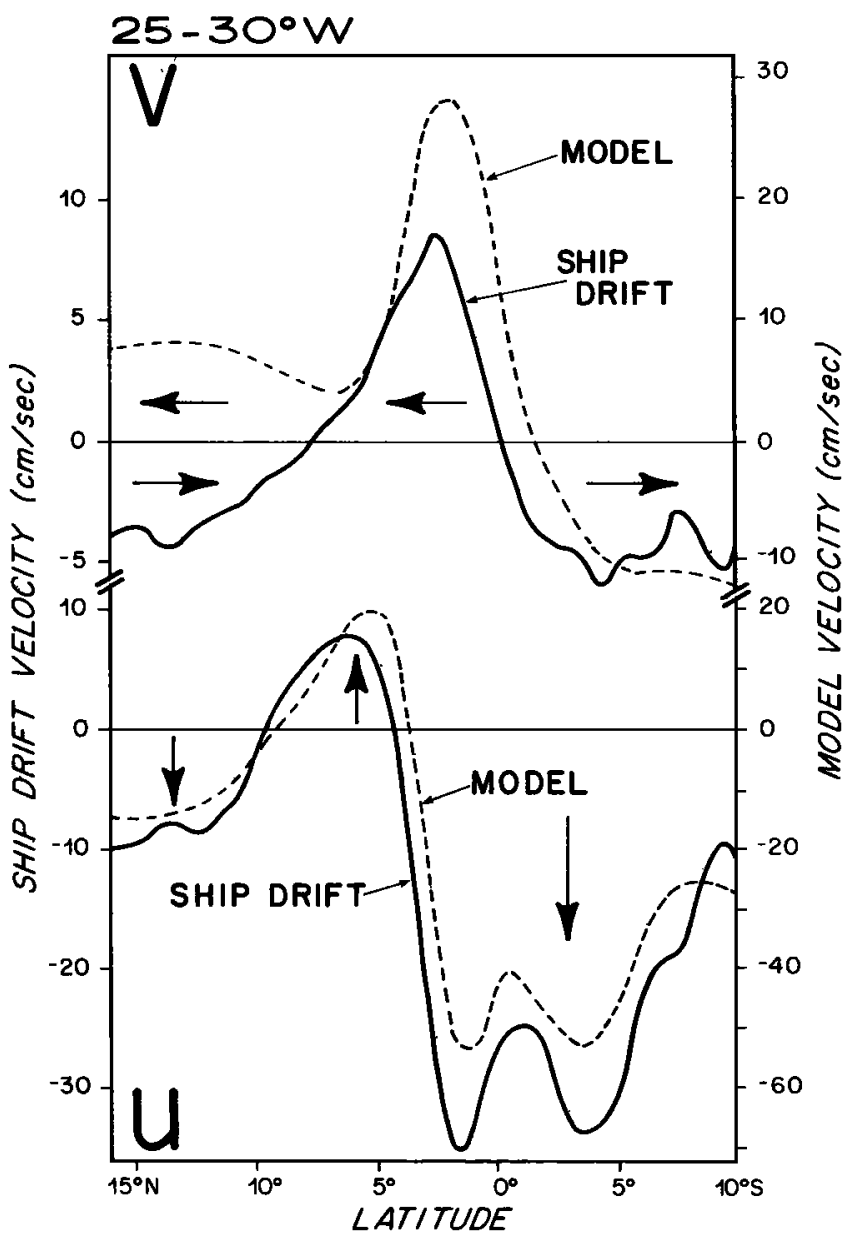

Fig. 9. North-south profile of annual average velocity in the band $25^{\circ}-30^{\circ} \mathrm{W}$. Ship drift velocity scales were expanded to make a closer match between ship drift and model curves. method must be found to take high-frequency wind fluctuations into account.

A second reason for too little vertical mixing in the model is related to the parameterization of the mixing. The mixing depends only on the Richardson number of the flow. When the vertical stability of the flow is very small, then the mixing has a constant value, independent of the intensity of the wind. This is unrealistic because there can be different

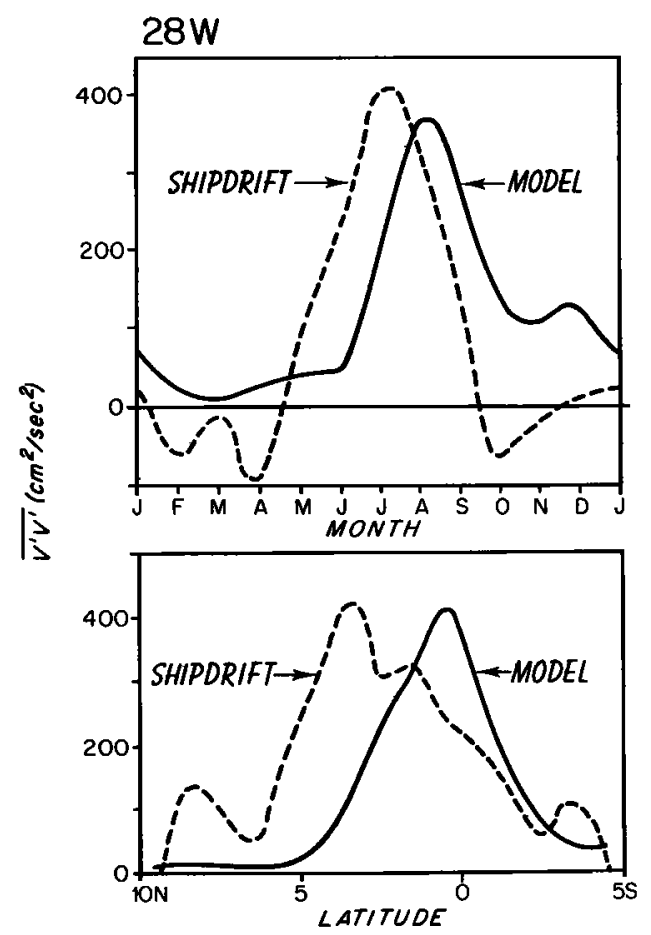

Fig. 10. (a) Model and ship drift values of the variance from the monthly mean meridional velocity component in the region $1^{\circ} \mathrm{N}$ to $3^{\circ} \mathrm{N}$. A constant of $500 \mathrm{~cm}^{2} \mathrm{~s}^{-2}$ has been subtracted from the ship drift data (see text). (b) Latitudinal structure of the curves in the top panel for June, July and August in the case of ship drifts, and for July, August and September in the case of the model. 


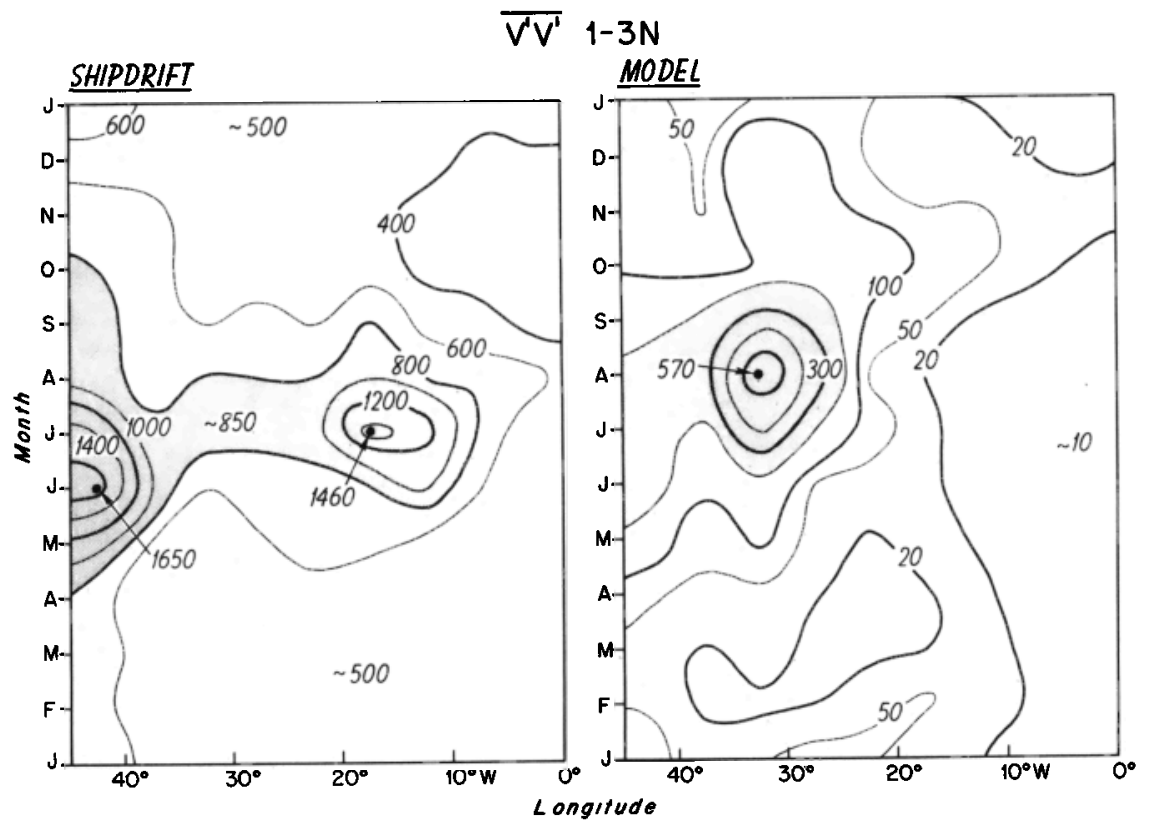

Fig. 11. Time-longitude plot of variance from the monthly mean meridional velocity in $5^{\circ}$ longitude boxes along the band $1^{\circ} \mathrm{N}$ to $3^{\circ} \mathrm{N}$. Shading was added to emphasize regions of large variance.

degrees of mixing in a layer of constant density. The western side of the basin, where the thermocline is deep so that the Richardson number in the upper ocean is small, is most affected by this flaw. The failure of the model to simulate a deep mixed surface layer in the west (the thermocline in the model is deep but there is weak stratification above it) is in part attributable to this problem with the parameterization.

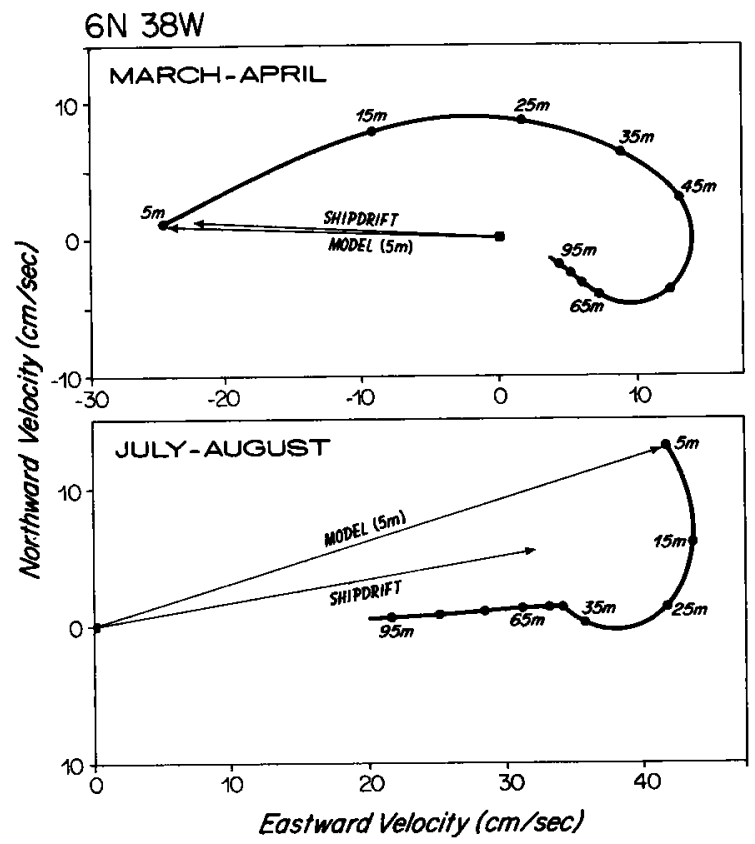

Fig. 12. Hodograph of velocity near $6^{\circ} \mathrm{N}, 38^{\circ} \mathrm{W}$ showing the variation of the model velocity with depth and the ship drift velocity. Two times are given: March-April, when the local wind is strong, and July-August, when the wind is weak.
Accurate daily winds, and a large amount of oceanographic data obtained as part of the FOCAL-SEQUAL programs, are available for 1983 and 1984. Further simulations with the winds for that period, using a model with improved mixing parameterization, will be attempted shortly, and the results will be compared with the oceanographic measurements from FOCAL and SEQUAL.

Acknowledgments. Funds were provided in part by the National Science Foundation grants OCE82-17112, OCE82-08744, and OCE85-14885. Results were calculated, plotted and drafted by Theresa McKee, David Walsh, and Ruth Davis. We thank Ron Pacanowski for assistance with the numerical model and Joan Pege and Mary Ann Lucas for preparing the manuscript. Woods Hole Oceanographic Institution contribution 6222.

\section{REFERENCES}

Bruce, J. G., and J. L. Kerling, Near equatorial eddies in the North Atlantic, Geophys. Res. Lett., 11, 779-782, 1984.

Bryan, K., A numerical method for the study of the world ocean, $J$. Comput. Phys., 4, 347-376, 1969.

Firing. E., R. Lukas, J. Sadler, and K. Wyrtki, Equatorial Undercurrent disappears during 1982-1983 El Niño, Science, 222, 1121-1123, 1983.

Garzoli, S. L., and S. G. H. Philander, Validation of an equatorial Atlantic model using inverted echo sounder data, J. Geophys. Res., 90, 9199-9201, 1985.

Halpern, D., Anomalous circulation in the equatorial Pacific during the 1982-83 El Niño, in Proceedings of the U.S. Workshop on the Dynamics of the Equatorial Ocean, edited by E. Katz and J. Witte, NYIT Press, Fort Lauderdale, Fla., in press, 1986.

Hellerman, S., and M. Rosenstein, Normal monthly windstress over the world ocean with error estimates, J. Phys. Oceanogr., 13, 1093-1104, 1983.

Legeckis, R., and G. Reverdin, Long waves in the equatorial Atlantic Ocean during 1983, J. Geophys. Res., in press, 1987.

Levitus, S., Climatological atlas of the world ocean, NOAA Prof. Pap., 13, 173 pp., 17 microfiche, U. S. Govt. Print. Office, Washington, D. C., 1982.

McPhaden, M. J., M. Fieux, and J. Gonella, Meanders observed in surface currents and hydrography during an equatorial Atlantic transect, Geophys. Res. Lett., 11, 757-760, 1984. 
Pacanowski, R., and S. G. H. Philander, Parameterization of vertical mixing in numerical models of tropical oceans, J. Phys. Oceanogr., 11, 1443-1451, 1981.

Philander, S. G. H., and R. C. Pacanowski, Simulation of the seasonal cycle in the tropical Atlantic Ocean, Geophys. Res. Lett., 11, 802-804, 1984.

Philander, S. G. H., and R. C. Pacanowski, A model of the seasonal cycle in the tropical Atlantic Ocean, J. Geophys. Res., 91, 14,192-14,206, 1986.

Philander, S. G. H., and A. D. Seigel, Simulation of El Niño of 1982-1983, in Coupled Ocean-Atmosphere Models, edited by J. Nihoul, pp. 517-541, Elsevier, New York, 1985.

Philander, S. G. H., W. Hurlin, and R. C. Pacanowski, Properties of long equatorial waves in models of the seasonal cycle in the tropical Atlantic and Pacific oceans, J. Geophys. Res., 91, 14,207-14,211, 1986.

Richardson, P. L., and T. K. McKee, Average seasonal variation of the Atlantic equatorial currents from historical ship drifts, $J$. Phys. Oceanogr., 14, 1226-1238, 1984.

Richardson, P. L., and D. Walsh, Mapping climatological seasonal variations of surface currents in the tropical Atlantic using ship drifts, J. Geophys. Res., 91, 10,537-10,550, 1986.

Weisberg, R. H., Instability waves observed on the equator in the Atlantic Ocean during 1983, Geophys. Res. Lett., 11, 753-756, 1984.

S. G. H. Philander, Geophysical Fluid Dynamics Laboratory, NOAA, Princeton University, Princeton, NJ 08542.

P. L. Richardson, Woods Hole Oceanographic Institution, Woods Hole, MA 02543.
(Received June 5, 1986; accepted July 22,1986 . 